\title{
Optical properties of dye DN-F05 as a good sensitizer
}

\author{
Diani Galih Saputri ${ }^{1}$, Agus Supriyanto ${ }^{2}$, Mohd Khairul Bin Ahamad ${ }^{3}$, Nadiyah El- \\ Haq Diyanahesa ${ }^{4}$, Febrina Ramadhani ${ }^{5}$ \\ 1,2,4,5 Physics Graduate Student, Universitas Sebelas Maret, \\ Jl. Ir. Sutami no 36 Kentingan Surakarta \\ ${ }^{3}$ Department of Electronics Engineering, Universiti Tun Hussein Onn Malaysia, \\ 86400 Parit Raja, Johor, Malaysia \\ E-mail: ${ }^{1}$ dianigalihs@student.uns.ac.id
}

Received 24 July 2019, Revised 13 September 2019, Published 30 September 2019

\begin{abstract}
This research studied the effect of adding synthetic dye DN-F05 (red dye) to electrical and optical properties. Dye-Sensitized Solar Cell (DSSC) sandwich components are consist of $\mathrm{FTO} / \mathrm{TiO}_{2}$-Dye-elektrolitPlatina/FTO. In this study, the working electrodes were made by Titanium dioxide (TiO2) which was deposited on FTO glass and then annealed at $450^{\circ} \mathrm{C}$ for 30 minutes. The dye concentration DN-F05 was made with a mass of $0.001 \mathrm{gr}$, then will be stirred for 2 hours into $5 \mathrm{ml}$ of ethanol at a temperature of $40^{\circ} \mathrm{C}$. In this study the spin coating method is used with a rotational speed of $1000 \mathrm{rpm}$ for 20 seconds. Characterization of optical properties was carried out using a UV-VIS spectrophotometer to determine the absorbance curve of dye and to get Gap energy. The peak absorbance value was obtained at wavelengths between $400-700 \mathrm{~nm}$. This proved that the addition of DN-F05 dye concentration has a major influence on the optical properties.
\end{abstract}

Keywords: Sensitizer, dye DN-F05 (red dye), $\mathrm{TiO}_{2}$, spin coating.

\section{Introduction}

The increase in population has become a new problem over time which has resulted in an increase in energy demand (Prasetyowati, 2012). An energy crisis will occur with an imbalance between the energy needed and available energy. One solution is to utilize renewable energy such as solar, wind, heat, water, geothermal energy and other renewable energy (Subodro, \& Ramelan, 2012).

Indonesia has great potential for the development of solar energy, in addition to having a tropical climate, the geographical location of the country is on the equator which causes almost all of Indonesia to receive solar radiation throughout the year. Based on these data, solar energy is one of the solutions for solving renewable energy problems in Indonesia. Utilization of solar energy into electrical energy is by solar cells or photovoltaic technology. One of the photovoltaic technologies currently under development and under review is Dye-Sensitized Solar Cell (DSSC). The scientist who first developed DSSC was Grätzel (1991) in (Halme, 2002), in his research mentioned 
several advantages of DSSC compared to conventional silicon solar cells, namely the fabrication technique is simple, production costs are cheaper, and the material is easily obtained (Grätzel, 2003).

DSSC components consist of a transparent glass substrate, Fluorine doped Tin Oxide (FTO), a thin layer of Titanium dioxide $\left(\mathrm{TiO}_{2}\right)$ semiconductors, a dye (red dye) coated on top of the semiconductor layer acting as an absorbent for photons whose ion is removing electrons, electrolytes, and opposing electrodes. Which can regenerate redox mediators (Nazeeruddin \& Baranoff, 2011). The working electrode (anode) is deposited from the material, in this case $\mathrm{TiO}_{2}$. The opposite electrode (cathode) is deposited from platinum (Pt) or carbon (C) material as a catalyst. Electrolyte solution acts as an electron transfer medium in the form of electrolytes.

Sensitizer is one of the components that is widely researched and developed in DSSC research, where in addition to acting as a photon absorber, dye also plays a role in the process of electron injection into semiconductors, and DSSC energy conversion. The number of dye molecules absorbed will increase the absorption of photons in DSSC (Wongcharee, Meeyo, \& Chavadej, 2007), so that DSSC performance is highly dependent on dye sensitizer. Good dye indicators used as sensitizers include, wide absorption spectrum, can bind to semiconductor surface strength, stable for a long time (Schlichthörl, Park, \& Frank, 1999). The area of the spectrum of absorption of light greatly affects the amount of energy absorbed, the wider spectrum, the greater solar energy that can be absorbed by dye. This is due to the increasing choice of wavelengths of light that can be absorbed by dye (Godibo, 2012).

There are two types of dyes that can be used, namely natural dyes and synthetic dyes. Natural dye has many advantages, namely materials easily available and available in nature, many variations of pigments, affordable prices, and very easy fabrication, as well as environmentally friendly, while synthetic dyes that are often used in research in general include N719, N3, Z907, and black dye (Ellis, et all. 2013). The highest efficiency ever achieved was $11.15 \%$ using N749 black dye. Among these advantages, synthetic dye also has several disadvantages, including the price which is quite expensive, not available in the wild, different color variations.

One synthetic dye that is known and has a high enough efficiency is dye DN-F05, a product from the Dyenamo company which reportedly reaches $14 \%$ efficiency (Kakiage, et all. 2015). The peak absorbance of dye DN-F05 was obtained at wavelengths of $320 \mathrm{~nm}-350 \mathrm{~nm}$ and $520 \mathrm{~nm}-580 \mathrm{~nm}$ (Gabrielsson, et all. 2013). This research is focused on optical characteristics of synthetic dye DN-F05 which is characterized using a UV-VIS spectrophotometer.

\section{Research Method}

$\mathrm{TiO}_{2}$ nanoparticles in the form of paste are produced and purchased directly from the Dyenamo company. Preparation of $\mathrm{TiO}_{2}$ solution is done by dissolving it into ethanol, then stirred using a magnetic stirrer at a speed of 200-300 rpm until homogeneous. $\mathrm{TiO}_{2}$ paste that has been formed is put in a bottle coated with aluminum foil and stored in a 
place that is protected from direct sunlight, this is done to reduce the evaporation process.

After making $\mathrm{TiO}_{2}$ solution, Fluorine doped Tin Oxide (FTO) glass substrate is prepared as a base for the layer to be deposited. Before the FTO glass is used, the glass is washed first using ethanol using an Ultrasonic Cleaner for 10 minutes and with a certain vibration, then the FTO glass is dried and checked on the conductive side by using a Multimeter. This is done to find out the conductive side so that the placement of the disposition solution is not mistaken, for more details can be seen in Figure 1. Conductive glass area of size $(2 \times 1.5) \mathrm{cm}^{2}$ is bounded using masking tape to form a disposition area with a central area of $(1 \times 1) \mathrm{cm}^{2}$. $\mathrm{TiO}_{2}$ coating is made using the spin coating method. $\mathrm{TiO}_{2}$ paste is dripped on an FTO glass that has been glued in a spinner, then rotated at a speed of $1000 \mathrm{rpm}$ for 20 seconds. The results obtained from the spin coating are left to dry somewhat, and then the tape is removed and the remaining let contained in the glass can be cleaned using ethanol. The FTO glass that has been deposited by $\mathrm{TiO}_{2}$ is heated using a furnace at a temperature of $450^{\circ} \mathrm{C}$ with a holding time of 30 minutes and a speed of 10 minutes, then cooled to room temperature.

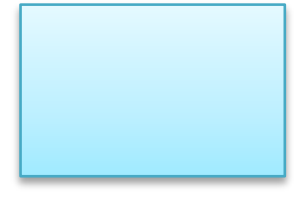

(a)

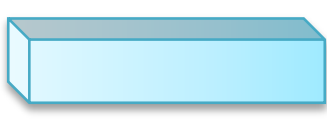

(b)

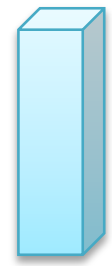

(c)

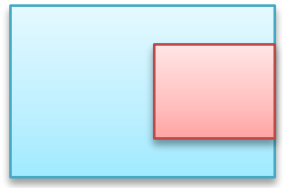

(d)

Figure 1. (a); (b); (c) FTO glass, (d) FTO glass with area $(1 \times 1) \mathrm{cm}^{2}$.

The next step is making a dye solution. The type of dye used in this study is synthetic dye namely DN-F05 (red dye), among other types of dye, red dye has the greatest efficiency value. as already mentioned in the study [6] which reported a value of red dye efficiency of $14 \%$. However, in this study, dye was used only as a sensitizer to analyze its optical properties. Dye preparation is done by weighing the dye first. The determined dye mass is 0.001 gr with $5 \mathrm{ml}$ ethanol solvent, then the solution is stirred using a magnetic stirrer for 2 hours at $40^{\circ} \mathrm{C}$.

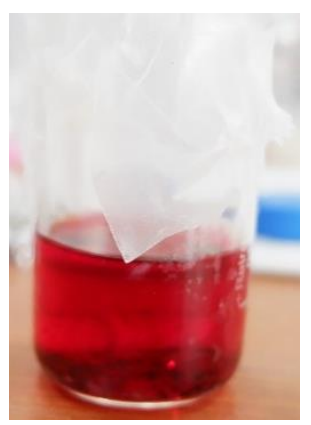

Figure 2. Dye solution

After that, the FTO glass that has been removed from the furnace is immersed using a prepared dye. Immersion was carried out for 12 hours, then the FTO glass was 
removed from the immersion and characterization using a UV-VIS spectrophotometer to obtain absorbance and transmittance values.

\section{Research and Discussion}

\subsection{Absorbance Characteristic}

Absorbance is how much light or energy is absorbed by a thin layer of the total light that is emitted. Before being used as a sensitizer, red dye is first characterized by using a UV-VIS spectrophotometer. This characterization was carried out to determine the absorption of light by the tested dye. The absorbance spectrum is measured in the wavelength range (200-800) $\mathrm{nm}$.

From Figure 3. it can be seen that the red dye absorption spectrum is quite wide from (430-620) $\mathrm{nm}$ with a maximum wavelength $(\lambda \max )$ of $520 \mathrm{~nm}$. This wide absorption will be able to improve the performance of solar cells, so it is very good to be used as a sensitizer on DSSC.

\subsection{Transmittance Characteristic}

In this study the glass substrate used was FTO glass deposited with a $\mathrm{TiO}_{2}$ layer and a $\mathrm{TiO}_{2}$ layer that was immersed in dye $\left(\mathrm{TiO}_{2} /\right.$ red dye). Figure 4 shows a graph of the relationship of the transmittance value of the $\mathrm{TiO}_{2}$ layer and the transmittance of the $\mathrm{TiO}_{2} /$ red dye layer to the wavelength. Transmittance is the opposite of absorbance which shows how much light is passed through the test solution. On glass substrates that have optimum optical (transmittance) properties depending on the temperature of the substrate and the thickness of the deposited layer.

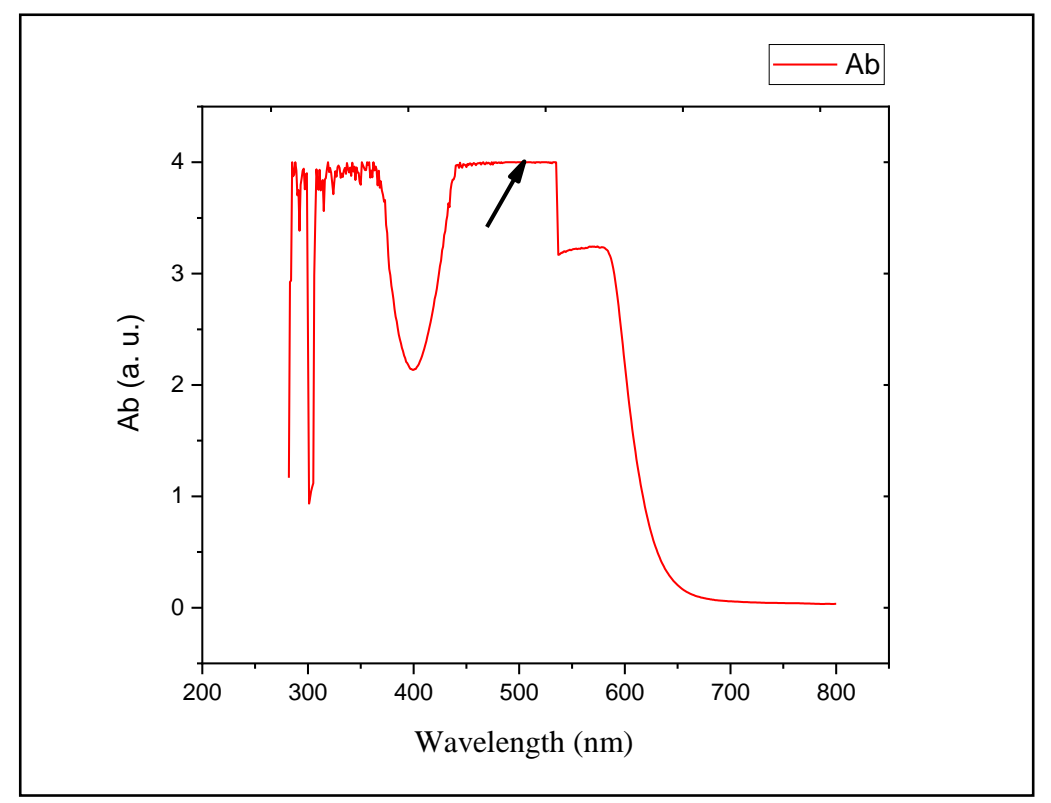

Figure 3. Graph of relationship between absorbance value and wavelength of dye DN-

F05 
Preparation of $\mathrm{TiO}_{2}$ and $\mathrm{TiO}_{2} /$ red dye coatings on FTO glass surfaces in furnaces at $450^{\circ} \mathrm{C}$ using the spin coating method. From the results of measurements of transmittance characterization shown in Figure 4. which shows that for pure $\mathrm{TiO}_{2}$ layers the transmittance value of about (10-78) \% is calculated at the wavelength position (350-800), if calculated at wavelength (600-800) transmittance value around (77-78) \%. For the transmittance value of $\mathrm{TiO}_{2} /$ red dye layer is obtained around (20-72) \% which is calculated from the wavelength (600-800), so that the optimum transmittance value can be obtained (72-78) \%.

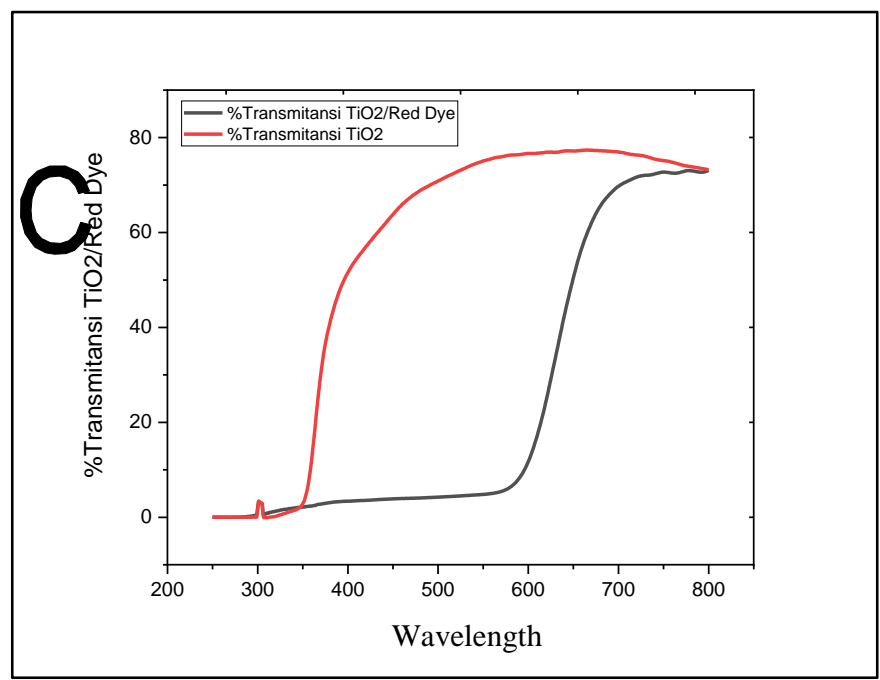

Figure 4. A graph of the relationship between $\mathrm{TiO} 2$ transmittance and red dye wavelength with TiO2 / Red Dye transmittance and red dye wavelength (DN-F05).

The transmission value obtained by the $\mathrm{TiO}_{2}$ layer and the $\mathrm{TiO}_{2} /$ red dye layer produces a significant difference in value, this is due to the length of the process carried out, for the $\mathrm{TiO}_{2}$ layer is tested without immersion, so that the transmission value is quite high, in addition to the thickness of the layer also influential, the thicker layer have lower value because the light transmitted will be slightly obstructed.

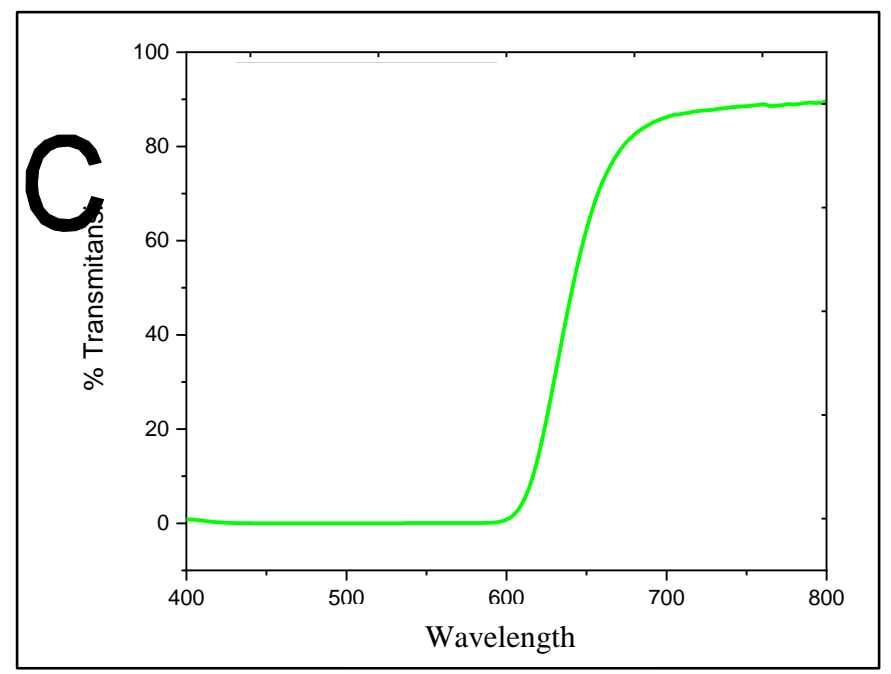

Figure 5. Graph of the relationship of $\%$ red dye transmittance $(0.001 \mathrm{gr})$ to wavelength. 
In Figure 5. the red dye solution transmittance value is shown around (10-89) \% if calculated from the wavelength (600-800), then from the graph can be processed and the band gap value is shown in Figure 6. The band gap energy value can be determined using the Tauc graph plot method, where this measurement is done by drawing a linear line on the relationship graph hv and $(\mathrm{h} \alpha \mathrm{v})^{2}$ until it intersects the hv axis. Previous research shows that the value of the $\mathrm{TiO}_{2}$ band gap energy is in the range of 3-4 eV, according to the existing theory that the gap dye energy must be less than the semiconductor value, this shows that the prepared dye can be used as a sensitizer in DSSC. This is because in the DSSC series there is electron excitation, which when absorbing photon energy from visible light, the electrons in the dye will be excited from the HOMO (high level) condition to the LUMO (low level) condition which then electrons will transfer to the $\mathrm{TiO}_{2}$ semiconductor conduction band. From the above explanation it has been proven the reason why the energy value of the red dye band gap is smaller than the semiconductor value, which is $1.89 \mathrm{eV}$.

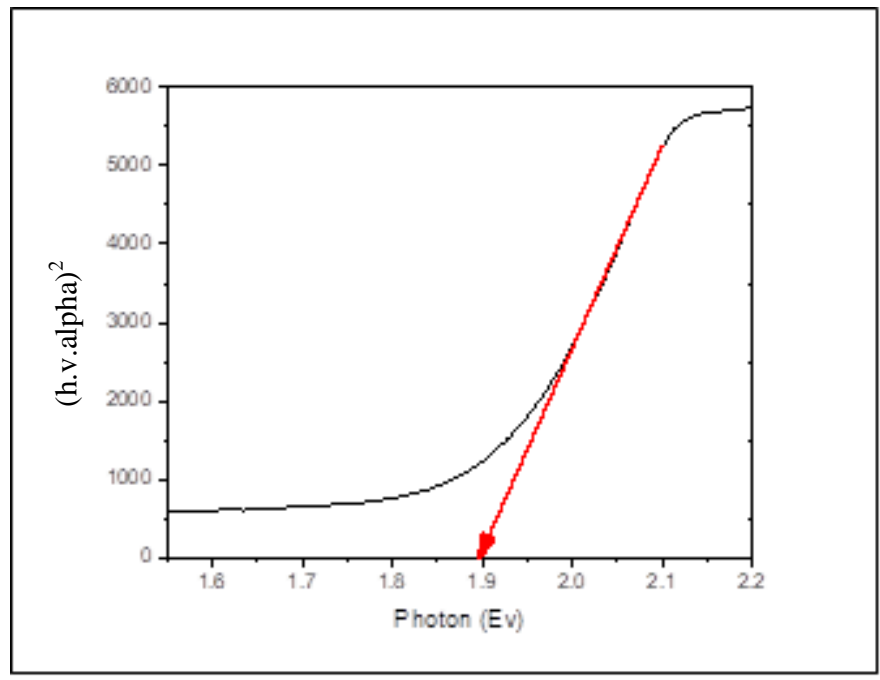

Figure 6. Red dye band gap graph (0.001 gr).

\section{Conclusion}

Based on the results of this study, conclusions can be obtained as follows:

a. Red dye (DN-F05) has an absorption width between (430-620) nm with a maximum wavelength $(\lambda \max )$ of $520 \mathrm{~nm}$.

b. Optimum transmittance at the $\mathrm{TiO}_{2}$ layer and $\mathrm{TiO}_{2} /$ red dye layer is at (72-78) \% calculated at wavelengths between $(600-800) \mathrm{nm}$, where the $\mathrm{TiO}_{2}$ layer has a greater transmittance value.

c. The transmittance value of red dye solutions is around (10-89) \% if calculated from the wavelength (600-800).

d. The band gap energy value can be determined using the Tauc graph plot method with a result of $1.89 \mathrm{eV}$. 


\section{Acknowledgements}

Higher Education Basic Research Contract with 2019 Budget Year Research Contract No: 092 / SP2H / LT / DRPM / 2019

\section{References}

Ellis, H., Eriksson, S.K., Feldt, S., Gabrielsson, E., Lohse, P., Lindlband, R., Sun, L.,Rensmo, H., Boschloo, G. \& Hagfeldt, A. (2013). Linker unit modification of triphenylamine-based organic dyes for efficient cobalt mediated DyeSensitized Solar Cells. Journal of Physical Chemistry, 117, 21029-21036.

Gabrielsson, E., Ellis, H., Feldt, Sandra., Tian, H., Boschloo, G., Hagfeldt, A., \& Sun, L. (2013). Convergent/divergent synthesis of a linker-varied series of dyes for Dye-Sensitized Solar Cells based on the D35 donor. Journal of Advanced Energy Material, 3, 1647-1656.

Godibo, D.J. (2012). Screening of natural dyes for use in dye sensitized solar cells. Journal of Physics Chemistry, 7, 140-145.

Grätzel, M. (2003). Dye-sensitized solar cell. Journal of Photochemistry and Photobiology C, 4, 143-145.

Halme, J. (2002). Dye-sensitized nanostructured and organic photovoltaic cells: Technical Review and Preliminary Tests. Tesis, Department of Engineering Physics and Mathematics, Helsinki University of Technology.

Kakiage, K., Aoyama Y., Yano, T., Oya, K., Fujisawa J., \& Hanaya M. (2015). Highlyefficient dye-sensitized solar cell with collaborative sensitization by silylanchor and carboxy-anchor dyes. Journal of Chemical Communications, 51, 15894-15897.

Nazeeruddin, Md. \& K., Baranoff, E. (2011). Dye-sensitzied solar cells : a brief overview. Journal of Solar Energy, 85, 1172-1178.

Prasetyowati, R. (2012). Sel surya berbasis titania sebagai sumber energi listrik alternatif. Prosiding Seminar Nasional Penelitian, Pendidikan dan Penerapan $M I P A$, Universitas Negeri Yogyakarta.

Schlichthörl, G., Park, N.G., \& Frank, A.J. (1999). Evaluation of the chargecollection efficiency of dye-sensitized nanocrystalline $\mathrm{TiO} 2$ solar cells. Journal of Physics Chemistry, 103, 91-782.

Subodro, R, \& Ramelan, AH. (2012). Sintesa titanium dioxide (TiO2) untuk dyesensitized solar cell (DSSC), UNS.

Wongcharee, K., Meeyo, V., \& Chavadej, S. (2007). Dye-sensitized solar cell using natural dyes extracted from rosella and blue pea flowers. Journal of Solar Energy Mater Solar Cells, 91, 566-571. 